\title{
A Valuable Improvement of Adult Height Prediction Methods IN SHORT NORMAL CHILDREN
}

\author{
M. Maes ${ }^{a}$, M. Vandeweghe ${ }^{d}$, M. Du Caju ${ }^{b}$, Ch. Ernould ${ }^{c}$, J.-P. Bourguignon ${ }^{c}$, G. Massa ${ }^{a}$ \\ Departments of Pediatrics, Universities of \\ a Leuven, \\ ${ }^{b}$ Antwerp, \\ 'Liege, and \\ ${ }^{d}$ Department of Endocrinology, University of Ghent, Belgium. \\ All the authors are members of the European Society for Paediatric Endocrinology.
}

KEYWORDS: Adult height prediction - Normal short stature - Growth hormone therapy.

\section{ABSTRACT}

Objectives: The potential benefit of growth hormone $(\mathrm{GH})$ administration to increase adult height of normal children of short stature might be blurred by the accuracy and the precision of the prediction methods used to estimate final height before onset of therapy. The aim of the present study was to evaluate three prediction methods: Bayley-Pinneau (BP), Roche-Wainer-Thissen (RWT) and Tanner-Whitehouse Mark II (TW2) and to improve their accuracy and precision by exploring their correlation with various parameters obtained in peripubertal children with poor predicted adult height.

Study Design: Accuracy and precision of the prediction methods were evaluated retrospectively by comparing predicted adult heights estimated in 62 boys at $13.7 \pm 0.9$ years and in 28 girls at $12.1 \pm$ 0.9 years of age, with their adult heights measured respectively at $20.7 \pm 2.6$ years and $18.8 \pm 2.8$ years.

Results: At the time of prediction, the height for chronological age was $-2.07 \pm 0.68$ standard deviation scores for boys and $-2.15 \pm 0.6$ years for girls. Measured adult heights were significantly lower than target heights $(165.1 \pm 5.1$ vs. $169.4 \pm 4.8 \mathrm{~cm}$ for boys; $p<0.001$ and $153.1 \pm 3.9$ vs. $156.3 \pm$ $5.0 \mathrm{~cm}$ for girls; $p=0.001$ ). For boys, the BP method was the most accurate and also the most convenient with a predicted adult height of $164.7 \pm 5.0 \mathrm{~cm}$ and a small underestimation of $0.4 \pm 3.5$ $\mathrm{cm}$. For girls, the TW2 method was the most accurate with a predicted height of $152.4 \pm 3.7 \mathrm{~cm}$ with a little underestimation of $0.7 \pm 3.5 \mathrm{~cm}$. There were no important differences between the precision of these methods. The use of a correction factor derived from the bone age delay at the time of prediction in boys and from the chronological age at the time of prediction in girls improved the accuracy of the predicted adult height.

Conclusions: The use of a factor correcting the accuracy of the BP method in boys and of the TW2 method in girls should be valuable in assessing the potential benefit of GH therapy to increase adult height in short normal children. 


\section{Introduction}

Since human growth hormone $(\mathrm{GH})$ supplies became unlimited due to recombinant DNA technology, investigators became interested in using GH in short normal children whose GH secretion was otherwise normal by standard criteria. Up until now, only short-term improvement of growth after GH administration has been demonstrated in such "short normal" children [1-7]. To evaluate whether or not GH administration to "short normal" children might have increased their final height, investigators are comparing predicted adult height at initiation of $\mathrm{GH}$ therapy with the observed adult height. Failure to take in account the accuracy and the precision of the prediction methods may have blurred the potential increase of adult height of short normal children by GH and may explain the inconsistency of the long-term benefit of GH therapy in short normal children, i.e. increased final adult height $[8,27]$. Therefore, the aim of the present study was to evaluate the accuracy and the precision of three different adult-height prediction methods: the Bayley Pinneau (BP) [9], the Roche-Wainer-Thissen (RWT) [10] and the Tanner-Whitehouse Mark II (TW2) methods [11] in a cohort of boys and girls with poor predicted adult height. Furthermore, we explored the possibility to improve the adult height prediction by correlating the accuracy and the precision of the different methods with various parameters obtained in these children at the time of prediction. This resulted in equations correcting the accuracy of the predictions and we propose to use these equations in studies designed to evaluate the effects of GH therapy on adult height of short normal children.

\section{Patients and Methods}

The medical records of children with short predicted adult height attending the outpatient departments of four different university centers between December 1977 and December 1986 were reviewed. In order to be included in the study, the children had to fulfil the following criteria when first evaluated: (1) a predicted adult height by the BP method below the 25th percentile for British standards [16]; (2) a bone age, determined by the Greulich and Pyle (GP) method [12], between 9 and 12 years for girls, and between 11 and 14 years for boys; (3) no clinical, auxological or biological evidence of chronic disease, intra-uterine growth retardation, bone dysplasia, chromosomal aberration or endocrinopathy. At the time of prediction $67 \%$ of the included children had a height at or below the 3rd percentile.

Subjects with manifest delay of growth and puberty were excluded on the basis of the following criteria: stage of pubertal development $<3$ rd percentile according to Tanner's criteria [13] and/or a bone age delay [bone age, estimated by the GP method, - chronological age] $\geq 3$ years. At the time of follow-up, the patients were considered to have reached their final height when growing less than $1.5 \mathrm{~cm}$ during the last year and/or having reached a (near) adult bone age ( $\geq 99 \%$ of adult height attained). The chronological age at measurement of (near) final height was $20.7 \pm 2.6$ years for boys (range: $17-27$ years) and 18.8 \pm 2.8 years for girls (range: 15-27 years). 
One hundred and forty four children, fulfilling the above-mentioned criteria, were contacted by letter and in a second phase by telephone. In all, 96 subjects came for follow-up evaluation. Finally, 62 boys and 28 girls who reached final height were included in the study. All the subjects had completed their pubertal development. Of the 48 subjects lost to follow-up, the majority could not be traced either by letter or by telephone: 10 letters were returned because the families had moved and 4 patients refused to come for a follow-up consultation. The "non-responders" - one third of the total - did not demonstrate any significant difference in chronological age, bone age or bone age delay, target height, pubertal stage or predicted adult height when compared to the study group.

Height was measured using a fixed Harpenden stadiometer with a precision of $0.1 \mathrm{~cm}$ and weight was taken in light underclothing to the nearest $0.1 \mathrm{~kg}$. Bone ages were estimated by the methods of GP [12] and Tanner-Whitehouse radius-ulna-short bones (TW2-RUS) [14] by the same observer (MV); height predictions were obtained from the tables of BP [9] and the equations of TW2 [11] and RWT [10]. Mid parental height was calculated from the parental heights available for 59 boys and 27 girls; target height is defined as mid-parental height $-6.5 \mathrm{~cm}$ for girls and $+6.5 \mathrm{~cm}$ for boys [15]. Using the recently defined criteria of familial short stature, $59.3 \%$ of the boys and $55.6 \%$ of the girls may be classified as having familial short stature [28].

Standard deviation scores (SDS) or Z scores are calculated from the relationship: $\mathrm{SDS}=\left(\mathrm{x}-\mathrm{x}_{\mathrm{i}}\right) / \mathrm{SD}_{\mathrm{i}}$ where $x$ is the actual measurement, and $x_{i}$ and $S D_{i}$ are the mean and the standard deviation for the $i$-th age band of the appropriate sex, using Tanner's standards [16]. The accuracy of the prediction methods was defined as the difference between the predicted and the measured adult height. $\mathrm{A}$ negative value therefore indicates underestimation of final height, whereas a positive value overestimation. The precision of the method is defined as the standard deviation of the accuracy and as the range of the accuracy for each prediction method. Results are expressed as means \pm 1 SD, unless otherwise indicated. Comparison between final and target height was performed by the paired $t$ test. Bivariate linear regressions and multiple linear regressions using the forward selection with an $\mathrm{F}$ entering value $\geq 3.84$ and a probability of $\leq 0.05$ were performed using the statistical software package SPSS version 6.1 [17], A two-tailed $p$ value of $\leq 0.05$ was considered significant.

\section{Results}

At initial examination, the mean chronological age was 13.7 years (range: 11.7-15.3) for the boys and 12.1 years (10.5-13.5) for the girls (table 1$)$. The majority of the boys (80.6\%) and the girls (60.7\%) had signs of pubertal development. The difference between mean bone age and chronological age was 0.4-0.5 years when bone age was assessed by the TW2-RUS method and 11.5 years when determined by the GP method. Bone age retardation (GP method) $\geq 2$ years was present in 15 boys (24.2\%) and 8 girls (28.6\%). The mean height for chronological age was -2.07 SDS for boys and -2.15 SDS for girls, significantly lower than their respective target heights $(-0.80$ and -0.99 SDS) (table 2). 
Table 1. Characteristics of boys and girls at the time of initial examination (data are expressed as mean $\pm 1 S D$ )

\begin{tabular}{lll}
\hline & Boys & Girls \\
\hline $\mathrm{n}$ & 62 & 28 \\
CA, years & $13.7+0.9$ & $12.1+0.9$ \\
BA, years, GP & $12.5+0.9$ & $10.7+0.8$ \\
TW2-RUS & $13.4+1.0$ & $11.6+0.9$ \\
BA delay, GP & $-1.2+0.9$ & $-1.4+0.9$ \\
BA delay, TW2-RUS & $-0.4+1.0$ & $-0.5+0.9$ \\
Prepubertal at prediction, $\mathrm{n}$ & 12 & 11 \\
\hline
\end{tabular}

$\mathrm{CA}=$ Chronological age; $\mathrm{BA}=$ bone age.

For boys and girls, measured adult heights were significantly lower than target heights: mean difference for boys: $-4.1 \pm 5.4 \mathrm{~cm}(n=59 ; p<0.001)$ and for girls: $-3.4 \pm 4.9 \mathrm{~cm}(n=27 ; p=0.001)$ (table 2). A significant proportion of boys (45.2\%) had an adult height below $165 \mathrm{~cm}$ ( 10th percentile) while $64.3 \%$ of the girls had an adult height under $155 \mathrm{~cm}$ ( 10th percentile). Height in SDS for CA at initial presentation underestimated adult height by $30 \%$. Using height expressed for bone age, estimated by the TW2-RUS method, adult height was also underestimated. In contrast, height expressed as SDS for bone age, determined by the method of GP, overestimated adult height by $0.36 \pm 0.51$ SDS in the boys and by $0.62 \pm 0.43$ SDS in the girls (table 2). These values correspond to a mean of 2.4 and $3.7 \mathrm{~cm}$, respectively for boys and girls.

Table 2. Height at the time of prediction, measured and predicted adult heights and target height.

\begin{tabular}{lll}
\hline & Boys & Girls \\
\hline $\mathrm{n}$ & 62 & 28 \\
Height at prediction, cm & $142.2 \pm 5.6$ & $134.5 \pm 4.6$ \\
$\quad$ SDS for CA & $-2.07 \pm 0.68^{\star \star}$ & $-2.15 \pm 0.62^{\star \star}$ \\
SDS for BA GP & $-1.09 \pm 0.62^{\star \star}$ & $-0.89 \pm 0.63^{\star \star}$ \\
$\quad$ SDS for BA TW2-RUS & $-1.77 \pm 0.63^{\star \star}$ & $-1.74 \pm 0.67^{\star}$ \\
Measured adult height, cm & $165.1 \pm 5.1$ & $153.1 \pm 3.9$ \\
$\quad$ SDS & $-1.45 \pm 0.78$ & $-1.51 \pm 0.64$ \\
Target height, cm & $169.4 \pm 4.8$ & $156.3 \pm 5.0$ \\
$\quad$ SDS & $-0.80 \pm 0.73$ & $-0.99 \pm 0.83$ \\
Predicted adult height, cm & & \\
BP & $164.7 \pm 5.0^{+}$ & $150.4 \pm 3.9^{\star \star}$ \\
TW2 & $162.6 \pm 3.90^{\star \star}$ & $152.4 \pm 3.7^{\star}$ \\
RWT & $165.4 \pm 3.8^{+}$ & $157.3 \pm 3.0^{\star \star}$ \\
Accuracy and precision, cm & & \\
BP & $-0.4 \pm 3.5$ & $-2.8 \pm 2.6$ \\
TW2 & $-2.5 \pm 3.5$ & $-0.7 \pm 3.5$ \\
RWT & $0.1 \pm 3.5$ & $4.4 \pm 2.9$ \\
\hline
\end{tabular}

Accuracy and precision of the BP, TW2, RWT methods for adult height prediction. Data are expressed as mean \pm 1 SD. ${ }^{+} p>0.05 ;{ }^{*} p<0.05 ;{ }^{\star \star} p<0.001$ vs. measured adult height by paired $t$ test. $C A=$ Chronological age; $B A=$ bone age. 
For each method, predicted adult height was highly and significantly correlated with the measured adult height (table 3 ) for boys and girls. For both sexes, the highest correlation coefficients were obtained with the BP method.

Table 3. Linear regression of predicted adult height $(\mathrm{cm})$ on measured adult height $(\mathrm{cm})$ using the BP, TW2 and the RWT method of prediction.

\begin{tabular}{|c|c|c|c|c|c|}
\hline & $\begin{array}{l}\text { Correlation } \\
\text { coefficient }\end{array}$ & $\begin{array}{l}\text { Regression } \\
\text { coefficient }\end{array}$ & $\begin{array}{l}\text { SE of the } \\
\text { regression } \\
\text { coefficient }\end{array}$ & Constant & $\begin{array}{l}\mathrm{SD} \text { of the } \\
\text { residuals }\end{array}$ \\
\hline \multicolumn{6}{|l|}{ Boys } \\
\hline $\mathrm{BP}$ & 0.76 & 0.74 & 0.08 & 42.4 & 3.2 \\
\hline TW-2 & 0.74 & 0.56 & 0.07 & 70.4 & 2.6 \\
\hline RWT & 0.70 & 0.54 & 0.07 & 75.5 & 2.7 \\
\hline \multicolumn{6}{|l|}{ Girls } \\
\hline $\mathrm{BP}$ & 0.78 & 0.77 & 0.12 & 32.3 & 2.5 \\
\hline TW-2 & 0.58 & 0.55 & 0.15 & 68.6 & 3.0 \\
\hline RWT & 0.66 & 0.53 & 0.12 & 75.6 & 2.3 \\
\hline
\end{tabular}

For all the regression coefficients, $p<0.001$.

For boys, the most accurate methods of adult height prediction were the RWT and the BP methods: the BP slightly underestimated while the RWT slightly overestimated final height (table 2). In contrast, the TW2 method underestimated adult height by a mean of $2.5 \pm 3.5 \mathrm{~cm}$. The precision of the three methods was similar as demonstrated by the SD as well as the ranges of their respective accuracy: BP: 3.5 and -7.8 to $+7.9 \mathrm{~cm}$; RWT: 3.5 and -7.2 to $+8.7 \mathrm{~cm}$; TW2: 3.45 and -9.3 to $+4.3 \mathrm{~cm}$.

To determine which variable obtained at the time of prediction correlated with the accuracy of the different prediction methods, bivariate linear regressions were obtained between accuracy for each method and the following variables at initial examination: chronological age, bone age, bone age delay, height in SDS for chronological age or bone age and target height SDS. Only the significant correlations are shown for boys in table 4. For the TW2 prediction method, no significant correlations were found. The strongest correlation was obtained for the BP method between accuracy and bone age delay observed at the initial examination (table 4, fig. 1). Using multiple linear regression did not improve the predicted error (data not shown). 
Fig. 1. Correlation between the accuracy of the $B P$ method of adult height prediction and bone age delay at the time of final height prediction in boys (accuracy $=-1.95-1.24 x$ bone age delay; $R=-0.34 ; p=0.008$; $S D$ of the residuals: 3.29). Regression line and $95 \%$ confidence limits around the mean are represented.

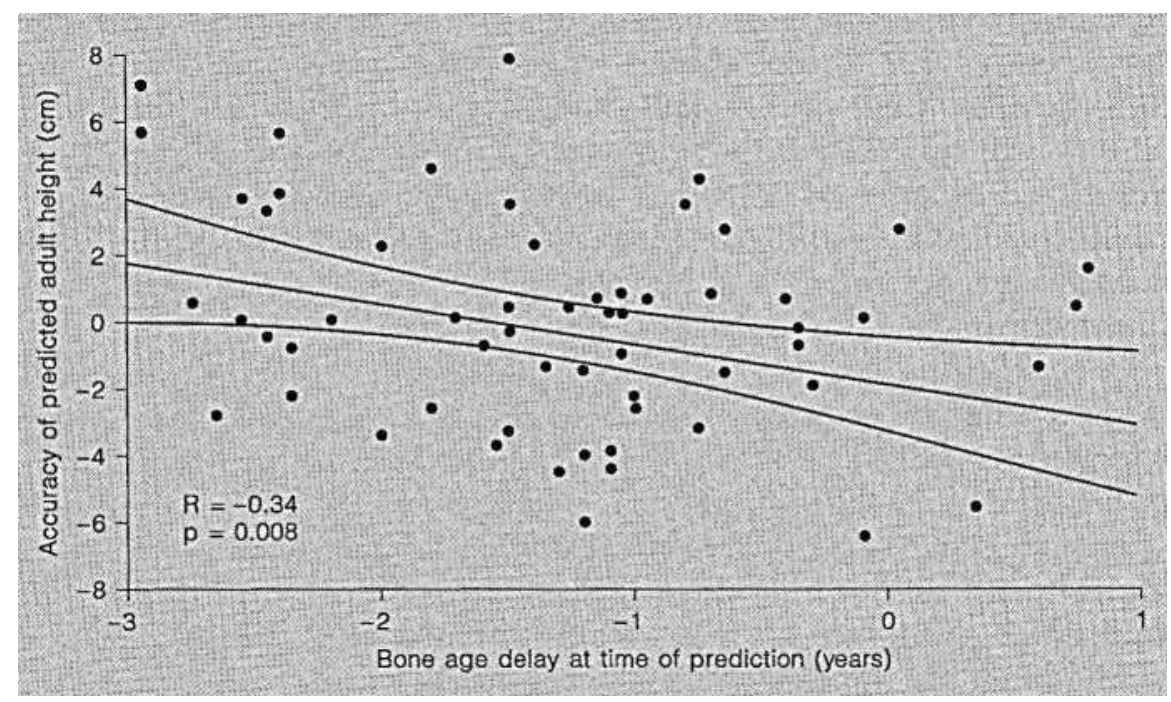

Table 4. Bivariate linear regression of the accuracy of the adult height prediction methods for boys.

\begin{tabular}{|c|c|c|c|c|c|c|}
\hline & $\begin{array}{l}\text { Correlation } \\
\text { coefficient }\end{array}$ & $\mathrm{p}$ & $\begin{array}{l}\text { Regression } \\
\text { coefficient }\end{array}$ & $\begin{array}{l}\text { SE of the } \\
\text { regression } \\
\text { coefficient }\end{array}$ & Constant & $\begin{array}{l}\text { SD of the } \\
\text { residuals }\end{array}$ \\
\hline \multicolumn{7}{|l|}{ Bayley Pinneau } \\
\hline $\mathrm{BA}$ & -0.31 & 0.016 & -1.16 & 0.47 & 14.14 & 3.33 \\
\hline BA delay & -0.34 & 0.008 & -1.24 & 0.45 & -1.95 & 3.29 \\
\hline Height SDS for BA & 0.26 & 0.039 & 1.47 & 0.69 & 1.19 & 3.37 \\
\hline \multicolumn{7}{|c|}{ Roche- Wainer-Thissen } \\
\hline Target height SDS & 0.25 & 0.05 & 1.20 & 0.61 & 1.09 & 3.38 \\
\hline
\end{tabular}

$\mathrm{BA}=$ Bone age.

For the girls, the TW2 method was the most accurate, underestimating final height by $0.7 \pm 3.5 \mathrm{~cm}$ (table 2). The RWT method grossly overestimated by $4.4 \mathrm{~cm}$ while the BP underestimated adult height by a mean of $2.8 \mathrm{~cm}$. The precision was slightly better for the BP method (SD: 2.6 and range 9.6 to $+1.6 \mathrm{~cm}$ ), followed by the RWT method (SD: 2.9 and range: -1.3 to $10.4 \mathrm{~cm}$ ) and the TW2 method (SD: 3.5 and range: -7.8 to $5.4 \mathrm{~cm}$ ). Significant bivariate linear correlations between the accuracy of each method and the variables obtained at initial examination could only be found for the TW2 method of prediction. The strongest correlation was observed for chronological age (table 5, fig. 2). Multiple linear regression analysis did not improve the predicted accuracy (data not shown). 
Fig. 2. Correlation between the accuracy of the TW2 method of prediction of adult height prediction and chronological age at the time of final height prediction in girls (accuracy $=21.97-1.87$ x chronological age; $R=$ 0.50; SD of the residuals: 3.05$)$. Regression line and $95 \%$ confidence limits around the mean are represented.

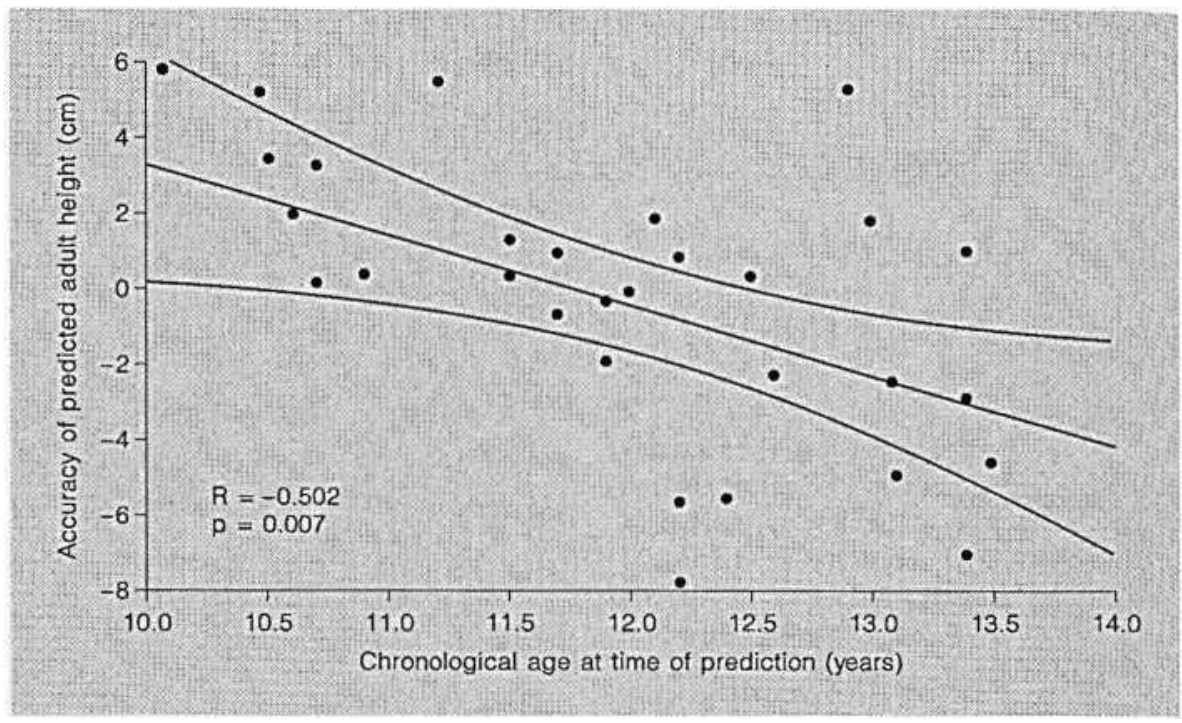

Table 5. Bivariate linear regression of the accuracy of the adult height prediction methods for girls.

\begin{tabular}{lllllrl}
\hline & $\begin{array}{l}\text { Correlation } \\
\text { coefficient }\end{array}$ & $P$ & $\begin{array}{l}\text { Regression } \\
\text { coefficient }\end{array}$ & $\begin{array}{l}\text { SE of the } \\
\text { regression } \\
\text { coefficient }\end{array}$ & Constant & $\begin{array}{l}\text { SD of the } \\
\text { residuals }\end{array}$ \\
\hline Tanner-Whitehouse 2 & & & & & & \\
CA & -0.50 & 0.007 & -1.87 & 0.63 & 21.97 & 3.05 \\
BA & -0.42 & 0.025 & -1.61 & 0.67 & 18.03 & 3.19 \\
Height SDS for CA & 0.42 & 0.025 & 2.36 & 0.99 & 4.33 & 3.19 \\
\hline
\end{tabular}

$\mathrm{CA}=$ Chronological age; $\mathrm{BA}=$ bone age .

\section{Discussion}

Several studies have been published on the effects of GH administration on the growth of children of short stature of predominantly familial origin with normal GH secretion [1-7, 27]. The evaluation of the effect of such therapy on final height is based upon the observed difference between predicted adult height before therapy and attained adult height at the end of therapy. This presupposes that the methods of adult height prediction are sufficiently accurate and precise not to obscure the eventual effects of GH therapy. Studies evaluating different prediction methods have been reported recently [18-25] but have focused almost exclusively on short children with constitutional delay of growth and puberty. In the present study, most of the children had short parents and no major delay in bone maturation, suggesting that their short stature was of familial origin without an important component of constitutional delay. The data available from the 
literature on the accuracy of the different prediction methods, together with the findings of the present study, are presented in table 6 .

Table 6. Accuracy $(\mathrm{cm})$ of prediction methods of previously reported and present study.

\begin{tabular}{lllll}
\hline & BP & TW2 & RWT & Subjects (n) \\
\hline Boys & & & & \\
Blethen et al. [18] & -1.6 & NA & NA & $17^{1}$ \\
& +3.0 & NA & NA & $10^{2}$ \\
Joss etal. [19] & +3.3 & +2.3 & +2.6 & $13^{2}$ \\
Crowne et al. [20] & NA & +2.0 & NA & $43^{2}$ \\
Willigetal. [21] & +0.8 & -6.0 & +1.0 & $77^{2}$ \\
La Franchi et al. [22] & +1.9 & NA & +0.1 & $29^{2}$ \\
Bramswig et al. [23] & +3.1 & -4.2 & -0.5 & $37^{2}$ \\
Spcrlich et al. [24] & +0.2 & -3.5 & -1.4 & $49^{2}$ \\
Holletal. [25] & +1.0 & -3.0 & -0.1 & $88^{2}$ \\
Present study & -0.4 & -2.5 & +0.1 & $62^{1}$ \\
Girls & & & & \\
Joss et al. [19] & -0.3 & +3.9 & +6.3 & $9^{2}$ \\
La Franchi et al. [22] & -0.8 & $\mathrm{NA}$ & +3.7 & $13^{2}$ \\
Bramswig et al. [23] & -0.8 & -1.8 & +2.6 & $32^{2}$ \\
Present study & -2.8 & -0.7 & +4.4 & $28^{1}$ \\
\hline
\end{tabular}

NA $=$ not available.

${ }^{1}$ Bone age slightly or not delayed.

${ }^{2}$ Bone age constantly delayed.

From our data in boys, the BP and the RWT methods appear to be the most accurate methods, while the TW2 method tended to underpredict final height. With the exception of the data reported by Crowne et al. [20] and Joss et al. [ 19] - the latter studying only a very small number of subjects, underprediction of final height by the TW2 method has been a constant finding for boys with constitutional delay of growth and puberty [21-25]. This underprediction varies from $3 \mathrm{~cm}$ in the study by Holl et al. [25] to a maximum of $6 \mathrm{~cm}$ in the study reported by Willig et al. [21]. These figures are greater than the underestimation we observed by the same method in boys, who presented with no major delay in bone age, however. In this respect, it should be realized that the magnitude of the underprediction by the TW2 method is correlated with the age at onset and the intensity of the adolescent growth spurt [26]. Therefore, the different values reported might be related to the different timings in the onset of the pubertal growth spurt and/or the importance of the pubertal growth acceleration. Differences in the proportion of children in puberty at the time of height prediction included in the different studies might also explain the differences in the reported accuracy and precision of the prediction methods.

In our study, as for the 17 boys reported by Blethen et al. [18] in whom bone age delay was minimal or absent, there was a tendency to a slight underestimation of adult height with the BP method. On 
the other hand, in studies where boys had a rather important delay in bone maturation [19, 21-25] an overestimation of final height was reported, varying from only $0.2 \mathrm{~cm}$ [24] to more than $3 \mathrm{~cm}$ $[19,23]$. These differences fit very well with the inverse correlation we have observed between the accuracy of the BP method and the bone age delay at the time of prediction, i.e. with a greater bone age delay, the BP method tended to overestimate adult height.

The precision of the three methods was equivalent as assessed by their SDs and the ranges of the accuracy. The error or the accuracy of the BP method could be improved when correlated with the bone age delay measured at the time of prediction and can therefore be used as a correcting factor for the predicted adult height prior to comparison with measured adult height.

Our data in girls suggest that the most accurate method is that of TW2, where only a slight underprediction was observed. Underprediction was also found in the study of Bramswig et al. [23] in a subset of short girls with mixed constitutional delay and familial short stature, whereas Joss et al. [19] observed the contrary, however in a very small population. Since accuracy of the TW2 method is inversely correlated to chronological age at the time of prediction, differences of this variable might explain the divergent results obtained. In our study, no important differences between the precisions of the three methods could be found. Since there is a significant inverse correlation between the accuracy of the TW2 method and the chronological age at prediction, we propose that the predicted adult height estimated by the TW2 method should be corrected by a factor derived from the regression equation between these 2 variables before comparison with adult height.

Underestimation by the BP method and gross overestimation of adult height by the RWT method as reported in the present study is in accordance with the results of other studies [19, 22, 23]. Nevertheless, the limited number of observations available in girls must warrant some caution in drawing definite conclusions. In addition, the extrapolation of the amendments that we propose for improving the accuracy of the prediction of final heights in boys and girls to short normal children of younger ages than the ones we have studied should await additional studies.

With the use of the BP prediction method in boys and the TW2 method in girls, we have at our disposal a fairly reliable way of evaluating the growth-promoting effects of GH therapy in short normal children. However, the still large individual confidence intervals implicate that a large population of treated children should be studied. Therefore, the inclusion of untreated control subjects, carefully matched to treated subjects, might still be additionally necessary, in order to correctly assess the effects of growth-promoting therapies in "short normal" children.

\section{Acknowledgements}

We wish to thank M. Craen for her help in contacting the patients and the members of the Belgian Study Group for Pediatric Endocrinology (M. Craen, J. De Schepper, F. de Zegher, L. Dooms, I. François, C. Heinrichs, P. Malvaux and G. Thiry-Counson) for helpful discussions. This study was supported in part by a grant from the Belgian Study Group for Pediatric Endocrinology. 


\section{References}

1 Wit JM, Fokker MH, de Muinck Kcizer-Schrama SMPF, Oostdijk W, Gons M, Otten BJ, Delemarre-Van de Waal HA, Reeser M, Waelkens JJJ: Effects of two years of methionyl growth hormone therapy in two dosage regimens in prepubertal children with short stature, subnormal growth rate, and normal growth hormone response to secretagogues. J Pediatr 1989; 115: 720-725.

2 Hindmarsh PC, Pringle PJ, DiSilvio L, Brook CGD: Effects of 3 years of growth hormone therapy in short normal children. Acta Paediatr Scand [Suppl] 1990; 366: 6-12.

3 Chanoine JP, Vanderschueren-Lodeweyckx M, Maes M, Thiry-Counson G, Craen M, Van Vliet G: Growth hormone treatment inshort normal children: absence of influence of time of injection and resistance to GH autofeedback. J Clin Endocrinol Metab 1991; 73: 1269- 1275.

4 Moore WV, Moore KC, Gifford R, Hollowell JC, Donaldson DL: Long-term treatment with growth hormone of children with short stature and normal growth hormone secretion. J Pediatr 1992; 120: 702-708.

5 Albertsson-Wikland K: Characteristics of children with idiopathic short stature in the Kabi International Growth Study, and their response to growth hormone treatment. Acta Paediatr Scand [Suppl] 1993; 391: 75-78.

6 Hopwood NJ, Hintz RL, Gertner JM, Attie KM, Johanson AJ, Baptista J, Kuntze J, Blizzard RM, Cara JF, Chcmausek SD, Kaplan SL, Lippe BM, Plotnik LP, Saenger P: Growth response of children with non-growth hormone deficiency and marked short stature during three years of growth hormone therapy. J Pediatr 1993; 123: $215-222$.

7 Loche S, Cambiaso P, Setzu S, Carta D, Marini R, Borelli P, Cappa M: Final height after growth hormone therapy in non-growth-hormone-deficient children with short stature. J Pediatr 1994; 125: 196-200.

8 Allen DB, Brook CGD, Bridges NA, Hindmarsh PC, Guyda HJ, Razicr D: Therapeutic controversies: Growth hormone (GH) treatment of non-GH deficient subjects. J Clin Endocrinol Metab 1994; 79: 1239-1248.

9 Bayley N, Pinncau SR: Tables for predicting adult height for skeletal age: Revised for use with the Greulich-Pyle hand standards. J Pediatr 1952; 40: 423-41.

10 Roche AF, Wainer H, Thissen D: The RWT method for the prediction of adult stature. Pediatrics 1975; 56: 1026-1033.

11 Tanner JM, Landt KW, Calcron N, Carter BS, Patel T: Prediction of adult height from height and bone age in childhood. A new system of equations (TW Mark II) based on a sample including very tall and very short children. Arch Dis Child 1983; 58: 767-776.

12 Geulich WW, Pyle SI (1950): Radiographic atlas of skeletal development of the hand and wrist, ed 2. Palo Alto, Stanford University Press, 1959.

13 Tanner JM: Growth at adolescence. Oxford, Blackwell Science, 1962.

14 Tanner JM, Whitehouse RH, Marshall WA, Healy MJR, Goldstein H: Assessment of skeletal maturity and predicting adult height: TW2 method, ed 2. London, Academic Press, 1983.

15 Tanner JM: Human growth standards. Construction and use; in Gedda L, Parisi P (eds): Auxology: Human growth in health and disease. London, Academic Press, 1978, pp 109-121. 
16 Tanner JM, Whitehouse RJ, Takaishi M: Standards from birth to maturity for height, weight, height velocity and weight velocity: British children, 1965. Arch Dis Child 1966; 41: 454-471, 613-635.

17 SPSS Inc: SPSS for windows release 6.1. Chicago, 1993.

18 Blethen SL, Gaines S, Weldon V: Comparison of predicted and adult heights in short boys: Effect of androgen therapy. Pediatr Res 1984; 18: 467-469.

19 Joss EE, Schmidt HA, Zuppinger KA: Oxandrolone in constitutionally delayed growth, a longitudinal study up to final height. J Clin Endocrinol Metab 1989; 69: 1109-1115.

20 Crowne EC, Shalet SM, Wallace WHB, Eminson DM, Price DA: Final height in boys with untreated constitutional delay in growth and puberty. Arch Dis Child 1990; 65: 1109-1112.

21 Willig RP, Mahnke K, Stahnke N, Commentz JC, Sinnecker G, Winkler P: Height predictions and final height in boys with constitutional delay of growth and puberty. Horm Res 1990, 33:34.

22 La Franchi S, Hanna CE, Mandel SH: Constitutional delay of growth: Expected versus final adult height. Pediatrics 1991; 87: 82-87.

23 Bramswig JH, Fasse M, Holthoff ML, von Lengerke HJ, von Petrykowski W, Schellong G: Adult height in boys and girls with untreated short stature and constitutional delay of growth and puberty: Accuracy of five different methods of height prediction. J Pediatr 1990; 886- 891.

24 Sperlich M, Butenandt O, Schwartz HP: Final height and predicted height in boys with untreated constitutional growth delay. Eur J Pediatr 1995; 154: 627-632.

25 Holl RW, Sorgo W, Teller WM, Heinze E: How reliable are Bayley-Pinneau predictions of adult height? A study in 88 men with short stature followed to final height (abstract). Horm Res 1990; 33(suppl3): 35.

26 Preece MA: Prediction of adult height: Methods and problems. Acta Paediatr Scand [Suppl] 1988; 347: 4-11.

27 Wit JM, Boersma B, de Muinck-Keizer-Schrama SM, Nienhuis HE, Ostdijk W, Otten BJ, Delemarre Van de Waal HA, Reeser M, Waelkens JJ, Rikken B, Massa GG: Long-term results of growth hormone therapy in children with short stature, subnormal growth rate and normal growth hormone response to secretagogues. Clin Endocrinol 1995; 42: 365-372.

28 Ranke MB: Towards a consensus on the definition of idiopathic short stature. Horm Res 1996; 45(suppl 2): 64-66. 